\title{
Study on the Effect of Chitosan Oligosaccharide in Relieving Constipation and Defecating Feces Excretion
}

\author{
Si-hui $\mathrm{Wu}^{1}$, Lan-lan Huang ${ }^{1}$, Yong-he Jiang $^{2}$, Yao Jiang ${ }^{3}$ and Zheng-quan \\ $\mathrm{Su}^{3, *}$ \\ ${ }^{1}$ Guangdong Food and Drug Vocational-Technical School, Guangzhou, 510663, China. \\ ${ }^{2}$ Dongsheng Hospital of Guangzhou, Guangzhou, 510000, China. \\ ${ }^{3}$ Guangdong TCM Key Laboratory for Metabolic Diseases, Guangdong metabolic Diseases \\ Research Center of Integrated Chinese and Western Medicine, Guangdong Pharmaceutical \\ University, Guangzhou Higher Education Mega Centre, Guangzhou , 510006, China. \\ ${ }^{*}$ Corresponding author
}

Keywords: Chitosan Oligosaccharide, Defecation, Male KM mice, Constipation.

\begin{abstract}
It was to explore the effect of chitosan oligosaccharide on relieving constipation and defecating feces excretion. Chitosan oligosaccharide were administered by oral $2.0 \mathrm{~g} / \mathrm{kg}, 1.0 \mathrm{~g} / \mathrm{kg}, 0.5$ $\mathrm{g} / \mathrm{kg} \mathrm{BW}$ dose to mice for $7 \mathrm{~d}$, then detected the propulsive rate of intestines, first defecation time, feces particle number and weight. The results showed that chitosan oligosaccharides could obviously promote the propulsive rate of intestines, shorten the first defecation time, increased the feces particle number and weight of the constipated mice. It indicated that chitosan oligosaccharides had effect on facilitating feces excretion to mice.
\end{abstract}

\section{Introduction}

Chitosan is a linear polysaccharide containing various proportions of 2-acetamido-2-D-glucose (GlcNAc) and 2-amino-2-D-glucose (D-glucosamine, GlcN), applied in nutritional [1], agricultural [2], medical areas [3-9].

Chitosan oligosaccharides (COS) are deacetylation products of chitosan, and recent reports indicate that they may be produced from chitosan using either chemical and physical methods, as well as enzymatic hydrolysis [10]. COS contains between two and twenty glucosamine residues which are attached through $\beta$-D-(1-4) glycoside linkages, similar to chitin and chitosan. The family of COS compounds have received much attention because of their small molecular weight, good aqueous solubility and diverse biological activity. Applications of interest include antibacterial efficacy [11], antitumor activity [12], anti-arthritic effect [13], immunostimulation [14], plant defense stimulation [15], moderation of cholesterol levels [16], weight loss [17-18].

Our research team has been long engaged in the study of chitosan and COS and has developed COS products such as the COS tablets and the COS capsules. We have found that the weight loss function of COS is equal to Orlistat, the only OTC weight loss pill on the market currently, and its side effects are significantly lower than Orlistat. Now our research group has pay attention to explore the effect of chitosan oligosaccharide on facilitating feces excretion.

\section{Materials and Methods}

\section{Materials}

Chitosan Oligosaccharide (COS) It was provided by Shandong Aokang biological technology co., LTD., with distilled water to dissolve into the certain concentration.

Reagents Activated carbon powder (Shanghai Aladdin biological technology co., LTD., C1607128), Arabic gum (Shanghai Aladdin biological technology co., LTD., A1619001), 
Loperamide Hydrochloride Capsules (xi 'an yeung sum pharmaceutical co., LTD., 150827647), Tongbianling Capsules (Guangdong yipiantian pharmaceutical group co., LTD., 151101020).

Animals Male KM mice were obtained from the laboratory animal center, Southern medical university, normal feeding for three days. Animal production license: SCXK (Guangdong), 2011-0015.

\section{Methods}

Dose The body recommended dosage of COS was $3.0 \mathrm{~g}$ per person for adult/d and three dose groups were set: $2.0 \mathrm{~g} / \mathrm{kg}, 1.0 \mathrm{~g} / \mathrm{kg}, 0.5 \mathrm{~g} / \mathrm{kg} \mathrm{BW}$ of mice in this experiment (equivalent of 40, 20, 10 times to the human body recommended dosage respectively). Tongbianling capsules were $1.5 \mathrm{~g}$ per person a day and we set dose of $0.5 \mathrm{~g} / \mathrm{kg}$ to mice (equivalent of 20 times to the human body recommended dose).

Raising Environment The temperature was $23 \pm 2{ }^{\circ} \mathrm{C}$, relative humidity $40-70 \%$, air changes $>15$ times/ hour, 12 hours lighting / 12 hours darkness alternation. Experimental animals use license was SYXK (Guangdong), 2012-1125.

Effects on the Movements of Small Intestines by COS Male KM mice were randomly divided into six groups of 11: the control group, the model group, the positive group (Tongbianling capsules, $0.5 \mathrm{~g} / \mathrm{kg}$ ), chitosan oligosaccharide high-dose (COS-H), middle-dose (COS-M) and low-dose group (COS-L). The control group and model group were given distilled water, the positive group given Tongbianling capsules $0.5 \mathrm{~g} / \mathrm{kg}$, the COS-H, COS-M, COS-L groups given $2.0,1.0,0.5 \mathrm{~g} / \mathrm{kg}$ COS daily, respectively.

Before administration the mice were fasting for $16 \mathrm{~h}$ at 7 th day. The control group were given distilled water, and the rest of the groups were given loperamide hydrochloride capsule aqueous solution $3.0 \mathrm{mg} / \mathrm{kg}$. After 30min each group were given indicator ink (containing 5\% carbon activated, $5 \%$ of gum Arabic). After another $25 \mathrm{~min}$ all mice were dislocated executed and their gastrointestinal tracts were taken out. It needed to measure the intestine length $(\mathrm{cm})$ which from stomach pylorus to ileocecal junction and ink's movement distance $(\mathrm{cm})$ which from stomach pylorus to the position of the ink. The gastrointestinal propulsion rate of mice $(\mathrm{P})$ was calculated: $\mathrm{P}=$ ink's movement distance $(\mathrm{cm}) /$ the intestine length $(\mathrm{cm})$. Then the statistical analysis data was converted to $(X), X=\operatorname{Sin}\left(\mathrm{P}^{1 / 2}\right)$.

Effects on Defecation by COS All KM mice were administered with indicator ink, then fed with a regular diet and distilled water. Record the time of the first black feces, feces particle number and weight in the first $5 \mathrm{~h}$ after administered with indicator ink in mice.

\section{Results}

\section{Effects on the Movements of Small Intestines by COS}

Ink propulsion rate of the model group was significantly lower than the control group $(\mathrm{P}<0.01)$. It stated that constipation model was established successfully. Ink propulsion rate of COS-H, COS-M and COS-L were higher than the model group, and statistical analysis showed those had significant difference with the model group $(\mathrm{P}<0.01)$. It showed that COS could promote the mouse small intestine movement function (the results shown in table 1).

\section{Effects on Defecation by COS}

The model group first defecated time were greater long than the control group $(\mathrm{P}<0.01)$, while defecation of feces particle number and weight in mice were smaller than the control group $(\mathrm{P}<0.01)$. It showed constipation model was established successfully. The first defecated time of each medication group were significantly shorter than the model group $(\mathrm{P}<0.01$ and $\mathrm{P}<0.05)$. The feces particle number and weight of each medication group were greater than the model group $(\mathrm{P}<0.01)$. These results showed that COS could reduce the first defecation time, increase the feces particle number and weight in constipation mice (the results shown in table 2). 
Table 1 Effects on the movements of small intestines by $\operatorname{COS}(\overline{\mathrm{X}} \pm \mathrm{S}, \mathrm{n}=11)$

\begin{tabular}{cccc}
\hline Group & $\begin{array}{c}\text { Dose } \\
(\mathrm{g} / \mathrm{kg})\end{array}$ & $\begin{array}{c}\text { Propulsion rate } \\
(\%)\end{array}$ & $\begin{array}{c}\text { Converted value } \\
(\mathrm{X})\end{array}$ \\
\hline Control & - & $72.9 \pm 2.1^{* *}$ & $1.03 \pm 0.08^{* *}$ \\
Model & - & $46.2 \pm 2.7$ & $0.75 \pm 0.09$ \\
Positive & 0.5 & $58.2 \pm 1.7^{* *}$ & $0.87 \pm 0.06^{*}$ \\
COS-H & 2.0 & $74.2 \pm 3.5^{* *}$ & $1.05 \pm 0.15^{* *}$ \\
COS-M & 1.0 & $63.3 \pm 4.2^{* *}$ & $0.93 \pm 0.15^{* *}$ \\
COS-L & 0.5 & $53.7 \pm 4.2$ & $0.82 \pm 0.14$ \\
\hline
\end{tabular}

Notes: Compared with model group, ${ }^{*} P<0.05,{ }^{* *} P<0.01$.

Table 2 Effects on defecation by $\operatorname{COS}(\overline{\mathrm{X}} \pm \mathrm{S}, \mathrm{n}=11)$

\begin{tabular}{ccccc}
\hline Group & $\begin{array}{c}\text { Dose } \\
(\mathrm{g} / \mathrm{kg})\end{array}$ & $\begin{array}{c}\text { First defecation } \\
\text { time } \\
(\mathrm{min})\end{array}$ & $\begin{array}{c}\text { Feces particle } \\
\text { number }\end{array}$ & $\begin{array}{c}\text { Feces weight } \\
(\mathrm{g})\end{array}$ \\
\hline Control & - & $56.45 \pm 18.42^{* *}$ & $38.82 \pm 3.82^{* *}$ & $0.78 \pm 0.07^{* *}$ \\
Model & - & $119.36 \pm 36.27$ & $21.45 \pm 2.11$ & $0.44 \pm 0.04$ \\
Positive & 0.5 & $64.91 \pm 19.91^{* *}$ & $36.36 \pm 3.01^{* *}$ & $0.73 \pm 0.07^{* *}$ \\
COS-H & 2.0 & $61.00 \pm 20.46^{* *}$ & $37.91 \pm 3.30^{* *}$ & $0.76 \pm 0.07^{* *}$ \\
COS-M & 1.0 & $85.18 \pm 31.37^{* *}$ & $34.00 \pm 2.93^{* *}$ & $0.68 \pm 0.06^{* *}$ \\
COS-L & 0.5 & $92.82 \pm 15.45^{*}$ & $25.82 \pm 3.22^{* *}$ & $0.53 \pm 0.06^{* *}$ \\
\hline
\end{tabular}

Notes: Compared with model group, ${ }^{*} \mathrm{P}<0.05,{ }^{* *} \mathrm{P}<0.01$.

\section{Conclusion}

In the present study, we demonstrated that COS could promote small intestine movement function, reduce the first defecation time, and increase the feces particle number and weight in constipation mice. According to The function of health food science evaluation procedure and inspection methods, the experiment showed that COS had effect on facilitating feces excretion to mice.

\section{Acknowledgement}

This project was financially supported by the Science and Technology Planning Project of Guangdong, China (no.2013B021100018), the Industry-university-research Collaborative Innovation Major Projects of Guangzhou Science Technology Innovation Commission (no.201604020164), China, and the National Science Foundation of China (no.81173107)

\section{References}

[1] Y. Luo, Z. Teng, X. Wang, Q. Wang, Development of carboxymethyl chitosan hydrogel beads in alcohol-aqueous binary solvent for nutrient delivery applications, Food Hydrocolloid. 31 (2013) 332-339.

[2] T. Lafarga, E. Gallagher, D. Walsh, J. Valverde, M. Hayes, Chitosan containing bread made using marine shellfishery byproducts: functional, bioactive, and quality assessment of the end product, J. Agric. Food Chem. 61 (2013) 8790-8796.

[3] Z.Q. Su, S.H. Wu, H.L. Zhang, Y.F. Feng, Development and validation of an improved bradford method for determination of insulin from chitosan nanoparticulate systems, Pharm. Biol. 48 (2010) 966-973.

[4] S.H. Wu, S.Y. Hu, G.D. Huang, W.S. Pan, C.L. Yu, S.R. Tan, S.D. Chen, Z.Q. Su, Experimental investigation on determination of chitosan by spectrophotometry, Adv. Mate. 554-556 (2012) 1895-1900.

[5] Y. Tao, H.L. Zhang, B. Gao, J. Guo, Y.M. Hu, Z.Q. Su, Water-soluble chitosan nanoparticles inhibit hypercholesterolemia induced by feeding a high-fat diet in male sprague-dawley rats, J. 
Nanomater. (2011) 99-110.

[6] H.T. Pan, Q.Y. Yang, G.D. Huang, C. Ding. P.Q. Cao, L.L. Huang, T. Xiao, J. Guo, Z.Q. Su, Hypolipidemic effects of chitosan and its derivatives in hyperlipidemic rats induced by a high-fat diet, Food Nutr. Res. 60 (2016) 311-337.

[7] Y. Tao, H. L. Zhang, Y.M. Hu, S. Wan, Z.Q. Su, Preparation of chitosan and water-soluble chitosan microspheres via spray-drying method to lower blood lipids in rats fed with high-fat diets, Int J Mol Sci. 14 (2013) 4174-4184.

[8] J. Chen, G. D. Huang, S. R. Tan, J. Guo, Z.Q. Su, The preparation of capsaicin-chitosan microspheres (CCMS) enteric coated tablets, Int. J. Mol. Sci. 14 (2013) 24305-24319.

[9] S.R. Tan, B. Gao, Y. Tao, J. Guo, Z.Q. Su, Antiobese effects of capsaicin-chitosan microsphere (CCMS) in obese rats induced by high fat diet, J. Agric. Food Chem. 62 (2014) 1866-1874.

[10] D. Lee, W. Xia, J. Zhang, Enzymatic preparation of chitooligosaccharides by commercial lipase, Food Chem. 111 (2008) 291-295.

[11] Y. Lu, D.L. Slomberg, M.H. Schoenfisch, Nitric oxide-releasing chitosan oligosaccharides as antibacterial agents, Biomaterials. 35 (2014) 1716-1724.

[12] J. Fernandes, J. Sereno, P. Garrido, B. Parada, M. Cunha, F. Reis, M. Pintado, A. Santos-Silva, Inhibition of Bladder Tumor Growth by Chitooligosaccharides in an Experimental Carcinogenesis Mode, Mar. Drugs. 10 (2012) 2661-2675.

[13] J.M. Einarsson, S. Bahrke, B. T. Sigurdsson, C. Ng, P.H. Petersen, O.E. Sigurjonsson, H. Jonsson, J. Gislason, F.R. Thormodsson, M.G. Peter, Partially acetylated chitooligosaccharides bind to YKL-40 and stimulate growth of human osteoarthritic chondrocytes, Biochem. Bioph. Res. Co. 434 (2013) 298-304.

[14] C. Lin, L. Chen, P. Lee, C. Lee, J. Lin, J. Chiu, The inhibition of TNF- $\alpha$-induced E-selectin expression in endothelial cells via the JNK/NF- $\mathrm{BB}$ pathways by highly $\mathrm{N}$-acetylated chitooligosaccharides, Biomaterials. 28 (2007) 1355-1366.

[15] K. Li, R. Xing, S. Liu, P. Li, Advances in preparation, analysis and biological activities of single chitooligosaccharides, Carbohyd. Polym. 139 (2016) 178-190.

[16] H.T. Pan, J. Guo, Z.Q. Su, Advances in understanding the interrelations between leptin resistance and obesity, Physiol. Behav. 130 (2014) 157-169.

[17] L.L. Huang, J. Chen, P.Q. Cao, H.T. Pan, C. Ding, T. Xiao, P. Zhang, J. Guo, Z.Q. Su, Anti-obese effect of glucosamine and chitosan oligosaccharide in high-fat diet-induced obese rats, Mar. Drugs. 13 (2015) 2732-2756.

[18] P.Q. Cao, H.T. Pan, T. Xiao, T. Zhou, J. Guo, Z. Su, Advances in the study of the antiatherogenic function and novel therapies for HDL, Int. J. Mol. Sci. 16 (2015) 17245-17272. 